\title{
RESPON PERTUMBUHAN TANAMAN ILER (Coleus scutellarioides (L.) Benth) PADA KONDISI CEKAMAN KEKERINGAN TERHADAP INOKULASI FUNGI MIKORIZA ARBUSKULAR (FMA)
}

\author{
Response to The Growth of Iler Plant (Coleus scutellarioides (L.) Benth) in Dry Stress Conditions to \\ Arbuscular Micoriza (AMF) Inoculation
}

Eva Proditus Sianturi ${ }^{1 *}$, Budiman ${ }^{1}$, Moh. Ega Elman Miska ${ }^{1}$

(Diterima Januari 2021/Disetujui Maret 2021)

\begin{abstract}
Iler plant (Coleus artopurporeus L benth) is a plant that was originally cultivated as an ornamental plant and then developed as a medicinal plant because it contains flavonoids and anthocyanins. Drought stress is a major environmental problem that causes various changes in plant morphological, metabolic and physiological functions. Utilization of Arbuscular Mycorrhizal Fungi (AMF) is an effort to support the growth and development of iler plants in drought stress conditions. This study aims to determine the effect of AMF inoculation on the growth of iler plants under drought stress conditions, determine the optimal level of drought stress for ilher plant growth, and determine the best interaction between AMF inoculation and the level of drought stress on the growth of iler plants. The design used in this study was a completely randomized factorial 2-factor design. The first factor is AMF inoculation consisting of 2 levels, namely, without administration of AMF inoculum and AMF inoculum administration. The second factor is drought stress consists of 3 levels namely, 100\% field capacity, 90\% drought stress, and 45\% drought stress. The results showed the effectiveness of the AMF inoculum test was able to increase the growth of iler plants based on parameters plant height, number of leaves, number of branches, leaf area, root length, root volume, root dry weight, number of spores and root infection. The optimal level of drought stress for iler plant growth is $90 \%$ drought stress, it is based on the parameters of plant height, number of leaves, number of branches, leaf area, root length, number of spores and root infection. There is the best interaction between AMF inoculation and $90 \%$ drought stress level on the growth of iler plants. These interactions can increase plant height, leaf area, number of spores and root infection.
\end{abstract}

Keywords: arbuscular mycorrhizal fungi (FMA), drought stress, iler plants.

\section{PENDAHULUAN}

Tanaman Iler (Coleus artopurporeus L benth) merupakan tanaman yang banyak dibudidayakan sebagai tanaman hias dan dapat menjadi tanaman obat. Tanaman famili Lamiaceae ini mengandung flavonoid dan antosianin. Kandungan flavonoid di dalam tanaman iler dapat dimanfaatkan untuk kesehatan manusia seperti obat wasir, peluruh haid, penambah nafsu makan, serta sebagai imunomodulator yang dapat meningkatkan sistem kekebalan tubuh (Qalby et al. 2017). Selain itu, tanaman iler memiliki warna daun menarik dan memiliki kesan estetika yang tinggi akibat kandungan antosianin yang terkandung di dalamnya, sehingga dapat digunakan sebagai tanaman Landscape untuk memperindah taman.

Budidaya tanaman iler membutuhkan kondisi lingkungan tertentu sehingga didapatkan pertumbuhan, hasil, dan kualitas tanaman yang tinggi. Cekaman kekeringan adalah masalah lingkungan utama yang umum ditemukan di daerah di mana tanaman iler biasanya tumbuh (Wijaya et al. 2019). Kekurangan air secara internal pada tanaman berakibat langsung pada penurunan pembelahan dan pembesaran sel. Pada tahap

\footnotetext{
${ }^{1}$ Program studi Agroteknologi, Universitas Gunadarma, Depok

* Penulis korespondensi:

e-mail: evasianturi36@gmail.com
}

pertumbuhan vegetatif, air digunakan oleh tanaman untuk pembelahan dan pembesaran sel yang terwujud dalam pertambahan tinggi tanaman, pembesaran diameter, perbanyakan daun, dan pertumbuhan akar. Keadaan cekaman air menyebabkan penurunan turgor pada sel tanaman dan berakibat pada menurunnya proses fisiologis (Sasli, 2004).

Upaya yang dapat diterapkan dan diaplikasikan untuk mendukung pertumbuhan dan perkembangan tanaman iler dalam kondisi cekaman kekeringan adalah dengan pemanfaatan Fungi Mikoriza Arbuskula (FMA) yang diinokulasikan terhadap tanaman iler. Salah satu peranan mikoriza bagi pertumbuhan dan produksi tanaman adalah dapat membantu dalam proses pertumbuhan diantaranya memperbaiki nutrisi tanaman dengan meningkatkan penyerapan unsur hara fosfat dan ketahanan terhadap kekeringan serta serangan patogen (Nusantara et al. 2012). Miska (2015) melaporkan bahwa aplikasi inokulum FMA indigenous mampu meningkatkan pertumbuhan bibit aren berdasarkan parameter tinggi tanaman sebesar $8.3 \%$, diameter pangkal pelepah $35.4 \%$, bobot kering tajuk dan akar $59.3 \%$, serta biomassa total sebesar 52\% dibandingkan kontrol. Rahman et al. (2019) menambahkan bahwa aplikasi inokulum FMA mampu meningkatkan berat kering tanaman bawang merah sebesar $97 \%$ dan berat kering umbi sebesar 203\% dibandingkan dengan tanpa mikoriza. 
Teknik budidaya iler secara ilmiah masih belum banyak dikaji sehingga hasil penelitian yang diperoleh dapat dijadikan anjuran sebagai Good Agricultural Practice (GAP). Penelitian ini bertujuan untuk mengetahui pengaruh inokulasi FMA terhadap pertumbuhan tanaman iler pada kondisi cekaman kekeringan, mengetahui tingkat cekaman kekeringan yang optimal untuk pertumbuhan tanaman iler, dan mengetahui interaksi yang terbaik antara inokulasi FMA dan tingkat cekaman kekeringan terhadap pertumbuhan tanaman iler.

\section{METODE PENELITIAN}

\section{Waktu dan Tempat Penelitian}

Penelitian ini dilaksanakan pada bulan Maret sampai bulan Mei 2020 di Laboratorium Agroteknologi Menengah dan Rumah Kaca Laboratorium Smart dan Urban Farming Kampus F7 Universitas Gunadarma, Ciracas, Jakarta Timur. Analisis media tanam di awal dan akhir penelitian dilakukan di Indonesian Center for Biodiversity and Biotechnology (ICBB), Bogor.

\section{Alat dan Bahan}

Alat yang digunakan dalam penelitian ini adalah saringan spora (saringan bertingkat tiga $250 \mu \mathrm{m}, 200$ $\mu \mathrm{m}$, dan $100 \mu \mathrm{m}$ ), mikroskop binokuler, sentrifuse, kaca preparat, kaca penutup, pipet tetes, cawan petri, timbangan analitik, bak kecambah, autoclave, oven, pot, polybag, kertas saring, aluminium foil, beaker glass, gelas ukur, lux meter, hygrometer, soil moisture. Bahan yang digunakan dalam penelitian ini adalah tanah yang disterilkan, $\mathrm{KOH} 10 \%$, HCL 2\%, metilen blue, aquades, benih sorgum, tanaman iler aksesi merah, zeolit, inokulum FMA mycofer.

\section{Rancangan Percobaan}

Rancangan yang digunakan adalah Rancangan Acak Lengkap (RAL) Faktorial 2 faktor. Faktor pertama adalah inokulasi FMA terdiri atas 2 taraf yaitu, tanpa pemberian inokulum FMA (M0) dan pemberian inokulum FMA (M1). Faktor kedua adalah cekaman kekeringan terdiri atas 3 taraf yaitu, kapasitas lapang $100 \%(\mathrm{C} 0)$, cekaman kekeringan 90\% (C1), dan cekaman kekeringan $45 \%$ (C2). Setiap unit percobaan terdiri atas 3 tanaman dan diulang sebanyak 3 kali sehingga total tanaman 54. Parameter pengamatan pertumbuhan iler meliputi tinggi tanaman, jumlah

Tabel 1 Pengaruh faktor inokulasi FMA dan cekaman kekeringan terhadap tinggi tanaman iler pada $12 \mathrm{MSP}$

\begin{tabular}{lccc}
\hline \multirow{2}{*}{ Inokulum FMA } & \multicolumn{3}{c}{ Cekaman kekeringan } \\
\cline { 2 - 4 } & $100 \%$ & $90 \%$ & $45 \%$ \\
\hline $\begin{array}{l}\text { Tanpa } \\
\text { Inokulum }\end{array}$ & $31.26 \mathrm{~cd}$ & $31.54 \mathrm{~cd}$ & $29.65 \mathrm{~d}$ \\
Inokulum FMA & $37.32 \mathrm{c}$ & $65.38 \mathrm{a}$ & $54.00 \mathrm{~b}$ \\
\hline Keterangan: Angka-angka yang diikuti huruf yang sama \\
$\begin{array}{l}\text { menunjukkan tidak berbeda nyata berdasarkan } \\
\text { uji DMRT pada taraf } \alpha=5 \% \text {; MSP = Minggu } \\
\text { Setelah Perlakuan }\end{array}$
\end{tabular}

cabang, jumlah daun (dilakukan setiap seminggu sekali), luas daun, bobot kering tajuk dan akar, biomassa total, panjang akar, volume akar, jumlah spora, dan persen infeksi akar (dilakukan diakhir penelitian).

\section{Analisis Data}

Data yang diperoleh dianalisis dengan menggunakan Analisis Varian (ANAVA). Jika hasil analisis menunjukkan adanya pengaruh yang signifikan maka akan dilanjutkan dengan uji DMRT (Duncan Multiple Range Test) dengan taraf $\alpha=5 \%$. Analisis menggunakan program SAS Windows 9.1.

\section{HASIL DAN PEMBAHASAN}

\section{Tinggi tanaman}

Interaksi antara inokulum FMA dan cekaman kekeringan berpengaruh terhadap tinggi tanaman pada 12 MSP. Interaksi yang terjadi antara inokulum FMA dengan cekaman kekeringan (90\%) pada 12 MSP menunjukkan adanya peran inokulum FMA terhadap tinggi tanaman. Perlakuan inokulum FMA dengan cekaman kekeringan (90\%) memiliki nilai tinggi tanaman yang lebih besar dibandingkan perlakuan tanpa inokulum FMA dengan cekaman kekeringan (90\%) (Tabel 1). Sasli (2004) menjelaskan bahwa mikoriza dapat membantu proses penyerapan unsur hara dari dalam tanah sehingga proses pertumbuhan tanaman terutama tinggi tanaman dapat berjalan secara optimal.

Kemampuan FMA dalam meningkatkan penyerapan unsur hara pada kondisi cekaman memberikan nilai positif bagi tanaman yang bersimbiosis dengan mikoriza. Sastrahidayat (2011) melaporkan bahwa tanaman bermikoriza lebih tahan kekeringan karena meningkatnya kemampuan tanaman untuk menghindari pengaruh langsung dari kekeringan dengan jalan meningkatkan penyerapan air melalui sistem gabungan akar dan mikoriza serta mereduksi tekanan air dalam tanaman.

Tabel 2Pengaruh faktor inokulasi FMA dan cekaman kekeringan terhadap jumlah daun hingga $12 \mathrm{MSP}$

\begin{tabular}{|c|c|c|c|c|c|c|}
\hline & \multirow{2}{*}{\multicolumn{2}{|c|}{ Perlakuan }} & & 4MSP & $8 \mathrm{MSP}$ & 12MSP \\
\hline & & & \multicolumn{4}{|c|}{ (helai) } \\
\hline \multirow[t]{3}{*}{1.} & Inokulun & n FMA & & & & \\
\hline & $\begin{array}{l}\text { Inokul } \\
\text { FMA }\end{array}$ & um & 7.70 & $27.07 \mathrm{a}$ & $45.51 \mathrm{a}$ & $66.96 \mathrm{a}$ \\
\hline & $\begin{array}{l}\text { Tanpa } \\
\text { inokul }\end{array}$ & & 8.03 & $10.85 \mathrm{~b}$ & $13.33 \mathrm{~b}$ & $23.44 \mathrm{~b}$ \\
\hline \multirow[t]{5}{*}{2.} & Cekamar & & & & & \\
\hline & kekering & & & & & \\
\hline & $100 \%$ & KPL & 7.61 & 15.00 & 16.50 & $26.66 \mathrm{~b}$ \\
\hline & $90 \%$ & & 8.05 & 21.55 & 36.55 & $54.50 \mathrm{a}$ \\
\hline & $45 \%$ & & 7.94 & 20.33 & 35.22 & $54.44 \mathrm{a}$ \\
\hline 3. & Interaksi & & tn & $\operatorname{tn}$ & $*$ & tn \\
\hline \multicolumn{2}{|c|}{ Keterangan: } & $\begin{array}{l}\text { Angka } \\
\text { pada } \\
\text { menun } \\
\text { uji DI } \\
\text { berbed } \\
\text { Mingg }\end{array}$ & $\begin{array}{l}\text { gka c } \\
\text { lom } \\
\text { kan ti } \\
\text { T pac } \\
\text { nyata } \\
\text { etelah }\end{array}$ & $\begin{array}{l}\text { kuti olel } \\
\text { an perla } \\
\text { ak berbed } \\
\text { taraf } \alpha \\
\text { ada tara } \\
\text { erlakuan }\end{array}$ & $\begin{array}{l}\text { huruf y } \\
\text { uan yat } \\
\text { nyata be } \\
=5 \% \text {; tr } \\
\alpha=5 \%\end{array}$ & $\begin{array}{l}\text { g sama } \\
\text { lasarkan } \\
=\text { tidak } \\
\text { MSP = }\end{array}$ \\
\hline
\end{tabular}




\section{Jumlah Daun}

Inokulum FMA meningkatkan jumlah daun sebesar $149.5 \%$, 241.4\%, dan $185.6 \%$ berturut-turut pada 4,8 dan 12 MSP dibandingkan tanpa inokulum. Cekaman kekeringan $90 \%$ dan $45 \%$ masing-masing meningkatkan jumlah daun sebesar $104.4 \%$ dan $104.2 \%$ dibandingkan cekaman kekeringan kapasitas lapang $100 \%$. Adanya interaksi antara perlakuan inokulum FMA dan cekaman kekeringan terhadap jumlah daun tanaman iler pada 8 MSP (Tabel 2). Hal ini diduga karena proses pembelahan dan pembesaran sel berjalan baik karena tidak terhambat oleh kekurangan unsur $\mathrm{N}$.

Unsur hara $\mathrm{N}$ yang tersedia dapat diserap secara optimal oleh akar tanaman yang bermikoriza. Inokulasi FMA mampu meningkatkan penyerapan unsur hara $\mathrm{N}$ oleh akar tanaman (Xie et al. 2014). Banyaknya jumlah daun akan meningkatkan proses metabolisme, terutama fotosintesis, sehingga fotosintat yang diedarkan ke seluruh bagian tanaman pun meningkat.

\section{Jumlah Cabang}

Inokulum FMA meningkatkan jumlah cabang sebesar $51.3 \%$ pada 12 MSP dibandingkan tanpa inokulum FMA (Tabel 3). Hal ini diduga bahwa inokulasi FMA mampu menyediakan unsur hara $\mathrm{P}$ sehingga mampu meningkatkan jumlah cabang tanaman iler. Terpenuhinya unsur hara $\mathrm{P}$ akan menunjang pembentukan jumlah cabang (Hasnizar, 2001).

Hasil penelitian Trisilawati dan Yusron (2008) menunjukkan bahwa perlakuan inokulum FMA dapat menunjang penyerapan unsur hara $\mathrm{P}$ yang dibutuhkan tanaman sehingga mampu meningkatkan jumlah cabang tanaman nilam sebesar $18.6 \%$ dibandingkan tanpa inokulum FMA. Wijaya et al. (2019) melaporkan bahwa perlakuan cekaman kekeringan $90 \%$ kapasitas lapang memberikan hasil terbaik pada variabel jumlah cabang.

\section{Luas Daun}

Interaksi antara inokulum FMA dan cekaman kekeringan berpengaruh nyata terhadap luas daun tanaman iler pada 12 MSP. Interaksi yang terjadi antara inokulum FMA dengan cekaman kekeringan (90\%) pada 12 MSP menunjukkan adanya peran inokulum FMA terhadap luas daun. Perlakuan inokulum FMA

Tabel 3 Pengaruh faktor inokulasi FMA dan cekaman kekeringan terhadap jumlah cabang tanaman iler pada 12 MSP

\begin{tabular}{ccc}
\hline & Perlakuan & C MSP \\
\cline { 3 - 3 } & & Cabang \\
\hline 1. & Inokulum FMA & \\
& Inokulum FMA & $8.99 \mathrm{a}$ \\
2. & Tanpa inokulum & $5.92 \mathrm{~b}$ \\
& Cekaman kekeringan & \\
& $100 \%$ KPL & 7.77 \\
& $90 \%$ & 8.77 \\
& $45 \%$ & 5.83 \\
3. $\quad$ Interaksi & tn \\
\hline Keterangan: & Angka-angka diikuti oleh huruf yang sama \\
& pada kolom dan perlakuan yang sama \\
& menunjukkan tidak berbeda nyata \\
& berdasarkan uji DMRT pada taraf $\alpha$ 5\%; tn \\
& $=$ tidak berbeda nyata pada taraf $\alpha=5 \% ;$ \\
& MSP = Minggu Setelah Perlakuan.
\end{tabular}

dengan cekaman kekeringan $(90 \%)$ memiliki nilai luas daun lebih besar dibandingkan perlakuan tanpa inokulum FMA dengan cekaman kekeringan (90\%) (Tabel 4). Hal ini diduga stomata daun tanaman iler pada perlakuan cekaman kekeringan tetap terbuka normal sehingga mampu menyangga air dalam jaringan lebih banyak. Tanaman yang diinokulasi mikoriza lebih mempunyai ketahanan terhadap kondisi air tanah rendah, 20 - 40\% kapasitas lapang (Sastrahidayat, 2011)

Tanaman kedelai dan jagung yang diinokulasi $G$. Fasciculatum relatif meningkatkan pertumbuhan tanaman pada kondisi air tanah $80 \%, 60 \%, 40 \%$, dan $20 \%$ kapasitas lapang (Tjondronegoro \& Gunawan, 2000).

\section{Panjang dan Volume Akar}

Inokulum FMA meningkatkan panjang akar sebesar $127.1 \%$ pada 12 MSP dibandingkan tanpa inokulum FMA. Cekaman kekeringan $90 \%$ meningkatkan panjang akar sebesar $130.4 \%$ pada 12 MSP dibandingkan cekaman kekeringan $45 \%$ dan kapasitas lapang $100 \%$ (Tabel 5). Hal ini juga didukung hasil penelitian Wijaya et al. (2019) yang menunjukkan bahwa perlakuan dengan cekaman kekeringan 90\% menunjukkan hasil akar terpanjang dengan nilai $49.75 \mathrm{~cm}$ dibandingkan cekaman kekeringan $75 \%$, cekaman kekeringan $50 \%$, dan cekaman kekeringan $25 \%$.

Peningkatan panjang akar diduga peran hifa

Tabel 4 Pengaruh faktor inokulasi FMA dan cekaman kekeringan terhadap luas daun tanaman iler pada 12 MSP

\begin{tabular}{lccc}
\hline & \multicolumn{3}{c}{ Cekaman kekeringan } \\
\cline { 2 - 4 } Inokulum FMA & $100 \%$ & $90 \%$ & $45 \%$ \\
\hline Tanpa & & & $81.97 \mathrm{bc}$ \\
Inokulum & & $84.38 \mathrm{cb}$ & \\
Inokulum FMA & $67.26 \mathrm{c}$ & $184.83 \mathrm{a}$ & $113.51 \mathrm{~b}$ \\
\hline
\end{tabular}

Keterangan: Angka - angka yang diikuti huruf yang sama menunjukkan tidak berbeda nyata berdasarkan uji DMRT pada taraf $\alpha=5 \%$; MSP $=$ Minggu Setelah Perlakuan

Tabel 5 Pengaruh faktor inokulasi FMA dan cekaman kekeringan terhadap panjang akar tanaman iler pada 12 MSP

\begin{tabular}{|c|c|c|c|}
\hline & Perlakuan & $\begin{array}{c}\text { Panjang } \\
\text { akar }(\mathrm{cm})\end{array}$ & $\begin{array}{c}\text { Volume akar } \\
\left(\mathrm{cm}^{3}\right)\end{array}$ \\
\hline \multirow[t]{3}{*}{1.} & Inokulum FMA & & \\
\hline & $\begin{array}{l}\text { Inokulum } \\
\text { FMA }\end{array}$ & $25.53 \mathrm{a}$ & $3.77 \mathrm{a}$ \\
\hline & $\begin{array}{l}\text { Tanpa } \\
\text { inokulum }\end{array}$ & $11.24 \mathrm{~b}$ & $1.92 \mathrm{~b}$ \\
\hline \multirow[t]{5}{*}{2.} & Cekaman & & \\
\hline & kekeringan & & \\
\hline & $100 \% \mathrm{KPL}$ & $11.74 \mathrm{~b}$ & 2.00 \\
\hline & $90 \%$ & $27.05 \mathrm{a}$ & 3.16 \\
\hline & $45 \%$ & $16.36 \mathrm{~b}$ & 3.39 \\
\hline 3. & Interaksi & tn & tn \\
\hline
\end{tabular}

Keterangan: Angka-angka diikuti oleh huruf yang sama pada kolom dan perlakuan yang sama menunjukkan tidak berbeda nyata berdasarkan uji DMRT pada taraf $\alpha=5 \%$; tn $=$ tidak berbeda nyata pada taraf $\alpha=5 \%$; MSP = Minggu Setelah Perlakuan 
eskternal dari FMA menyediakan permukaan yang bekerja lebih efektif dalam membantu akar untuk menyerap unsur hara dan air yang tidak terjangkau oleh akar (Miska, 2015). Inokulum FMA meningkatkan volume akar sebesar $96.3 \%$ pada 12 MSP dibandingkan tanpa inokulum FMA. Cekaman kekeringan $45 \%$ meningkatkan volume akar sebesar $69.5 \%$ pada 12 MSP dibandingkan cekaman kekeringan 90\% dan kapasitas lapang 100\% (Tabel 5). Hal ini diduga FMA yang menginfeksi akar dapat meningkatkan volume akar tanaman iler. Sejalan dengan hasil penelitian Widiastuti et al. (2003) menunjukkan bahwa inokulasi mikoriza mampu mempercepat pembentukan akar yang dapat mempengaruhi bobot akar yang dihasilkan.

\section{Bobot kering tajuk dan akar}

Bobot kering tajuk tidak dipengaruhi oleh perlakuan inokulum FMA dan cekaman kekeringan pada 12 MSP. Interaksi antara inokulum FMA dan cekaman kekeringan tidak berpengaruh nyata terhadap bobot kering tajuk pada 12 MSP. Perlakuan inokulum FMA memiliki bobot kering tajuk yang lebih tinggi dibandingkan tanpa inokulum, sedangkan perlakuan cekaman kekeringan $90 \%$ bobot kering tajuk yang lebih tinggi dibandingkan cekaman kekeringan level lainnya (Tabel 6). Peningkatan bobot kering tajuk diduga adanya simbiosis antara FMA dengan tanaman iler. Adanya simbiosis FMA dengan akar tanaman iler dapat meningkatkan serapan air dan fosfor yang akan dimanfaatkan daun dan batang. Salah satu peran fosfor adalah untuk pembelahan sel, merangsang perkembangan akar dan tajuk. Hal ini sesuai dengan penelitian Herawati (2009) yang menyatakan bahwa bobot kering tajuk kedelai tertinggi diperoleh pada pemberian inokulan FMA dan terendah pada perlakuan tanpa FMA.

Bobot kering akar dipengaruhi oleh perlakuan inokulum FMA pada 12 MSP. Interaksi antara inokulum FMA dan cekaman kekeringan tidak berpengaruh nyata terhadap bobot kering akar pada 12 MSP. Inokulum FMA meningkatkan bobot kering akar sebesar $140.3 \%$ pada 12 MSP dibandingkan tanpa inokulum FMA

Tabel 6 Pengaruh faktor inokulasi FMA dan cekaman kekeringan terhadap bobot kering tajuk dan akar tanaman iler pada $12 \mathrm{MSP}$

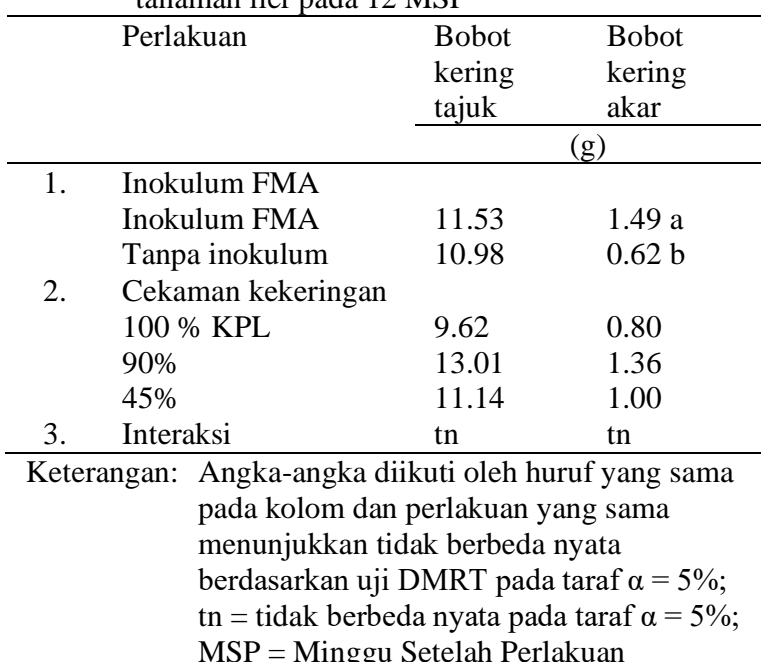

(Tabel 6). Hal ini didukung oleh penelitian yang dilakukan oleh Utama dan Yahya (2003), dimana terjadi peningkatan berat kering akar pada tanaman legum penutup tanah (Calopogonium mucunoides, Calopogonium ceurelieum, Centrosema pubescens dan Pueraria javanica) yang diberikan mikoriza.

Menurut Sasli (2004) peranan langsung dari mikoriza adalah membantu akar dalam meningkatkan penyerapan air dari dalam tanah ke dalam akar, karena mikoriza dapat memperluas permukaan akar dalam penyerapan air dari dalam tanah. Air yang diserap dari dalam tanah akan digunakan oleh tumbuhan untuk pembelahan dan pembesaran sel yang salah satunya terwujud dalam pertumbuhan akar, yaitu meningkatnya derajat percabangan dan diameter akar.

\section{Biomassa total}

Biomassa total tanaman iler tidak dipengaruhi oleh perlakuan inokulum FMA dan cekaman kekeringan pada 12 MSP. Interaksi antara inokulum FMA dan cekaman kekeringan tidak berpengaruh nyata terhadap biomassa total pada 12 MSP. Perlakuan inokulum FMA memiliki biomassa total yang lebih tinggi dibandingkan tanpa inokulum, sedangkan perlakuan cekaman kekeringan $90 \%$ biomassa total yang lebih tinggi dibandingkan cekaman kekeringan level lainnya (Tabel 7). Hal ini diduga peningkatan biomassa total berkaitan dengan metabolisme tanaman atau adanya kondisi pertumbuhan tanaman yang lebih baik bagi berlangsungnya aktivitas metabolisme tanaman seperti fotosintesis.

Pengaruh mikoriza yang paling utama adalah dapat meningkatkan pengambilan unsur fosfat dari tanah, dan meningkatkan biomassa. Kandungan unsur fosfat pada tanaman akan memengaruhi laju fotosintesis dan

Tabel 7 Pengaruh faktor inokulasi FMA dan cekaman kekeringan terhadap biomassa total tanaman iler pada 12 MSP

\begin{tabular}{lll}
\hline & Perlakuan & \multicolumn{2}{c}{ Biomassa total } \\
\cline { 3 - 3 } & & \multicolumn{1}{c}{$(\mathrm{g})$} \\
\hline $1 . \quad$ & Inokulum FMA & 13.41 \\
& Inokulum FMA & 11.57 \\
& Tanpa inokulum & \\
2. & Cekaman kekeringan & 10.37 \\
& $100 \%$ KPL & 14.96 \\
& $90 \%$ & 12.14 \\
& $45 \%$ & tn \\
$3 . \quad$ Interaksi &
\end{tabular}

Tabel 8. Pengaruh faktor inokulasi FMA dan cekaman kekeringan terhadap jumlah spora tanaman iler pada 12 MSP

\begin{tabular}{lccc}
\hline \multirow{2}{*}{ Inokulum FMA } & \multicolumn{3}{c}{ Cekaman kekeringan } \\
\cline { 2 - 4 } & $100 \%$ & $90 \%$ & $45 \%$ \\
\hline $\begin{array}{l}\text { Tanpa } \\
\text { Inokulum }\end{array}$ & $4.33 \mathrm{~d}$ & $9.33 \mathrm{~d}$ & $5.33 \mathrm{~d}$ \\
Inokulum FMA & $59.00 \mathrm{c}$ & $147.00 \mathrm{a}$ & $112.00 \mathrm{~b}$ \\
\hline
\end{tabular}

Keterangan: Angka-angka yang diikuti huruf yang sama menunjukkan tidak berbeda nyata berdasarkan uji DMRT pada taraf $\alpha=5 \%$; MSP = Minggu Setelah Perlakuan 
merangsang pembentukan daun baru yang mengakibatkan biomassa bertambah (Bucher, 2007; Rewald et al. 2015).

\section{Jumlah spora}

Interaksi antara inokulum FMA dan cekaman kekeringan berpengaruh nyata terhadap jumlah spora pada 12 MSP. Interaksi yang terjadi antara inokulum FMA dengan cekaman kekeringan (90\%) pada 12 MSP menunjukkan adanya peran inokulum FMA terhadap jumlah spora. Perlakuan inokulum FMA dengan cekaman kekeringan (90\%) memiliki nilai jumlah spora lebih besar dibandingkan perlakuan tanpa inokulum FMA dengan cekaman kekeringan (90\%) (Tabel 8). Salah satu sifat fisika tanah yang berpengaruh terhadap jumlah spora FMA adalah kadar air tanah. Kandungan air tanah yang rendah menyebabkan kondisi lahan kering. Lahan yang kering sangat mendukung bagi perkembangan mikoriza, dimana ketersediaan unsur hara yang rendah pada kondisi lahan kering tersebut akan mengoptimalkan perkembangan hifa mikoriza (Yusriadi et al. 2018).

Puspitasari et al. (2012) menyatakan bahwa populasi spora FMA yang tinggi disebabkan kondisi lingkungan yang lebih sesuai, optimal, dan kompatibel dalam mendukung pertumbuhan dan perkembangan spora FMA serta kemungkinan tidak adanya jamur antagonis yang menghambat sporulasi FMA. Nurhalimah et al. (2014) menambahkan bahwa semakin tinggi suhu maka jumlah mikoriza akan semakin banyak karena suhu berpengaruh terhadap pertumbuhan dan pembentukan koloni spora mikoriza.

Tabel 9 Pengaruh faktor inokulasi FMA dan cekaman kekeringan terhadap infeksi akar tanaman iler pada 12 MST

\section{Perlakuan}

1. Inokulum FMA

Inokulum FMA

Tanpa inokulum

2. Cekaman kekeringan

$100 \% \mathrm{KPL}$

$90 \%$

$45 \%$

3. Interaksi

Keterangan: Angka -angka yang diikuti huruf yang sama menunjukkan tidak berbeda nyata berdasarkan uji DMRT pada taraf $\alpha=5 \%$; MSP = Minggu Setelah Perlakuan
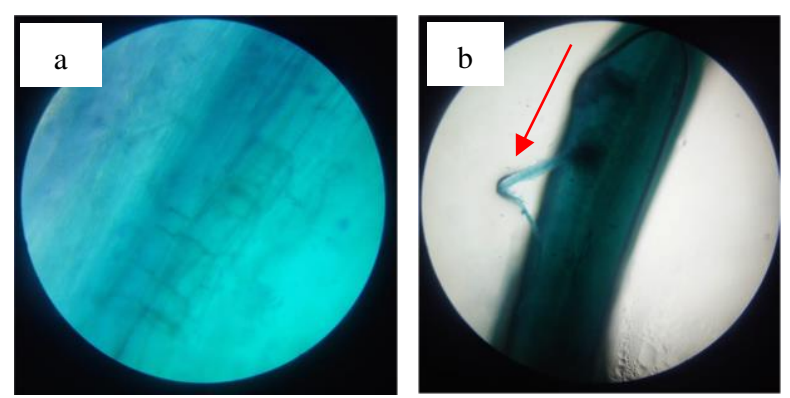

Gambar 2 Infeksi FMA pada tanaman iler; a) = akar yang tidak terinfeksi, $b)=$ hifa eksternal

\section{Infeksi akar}

Interaksi antara inokulum FMA dan cekaman kekeringan berpengaruh nyata terhadap Infeksi akar pada 12 MSP. Interaksi yang terjadi antara inokulum FMA dengan cekaman kekeringan (90\%) pada 12 MSP menunjukkan adanya peran inokulum FMA terhadap infeksi akar. Perlakuan inokulum FMA dengan cekaman kekeringan (90\%) memiliki nilai infeksi akar lebih besar dibandingkan perlakuan tanpa inokulum FMA dengan cekaman kekeringan (90\%) (Tabel 9). Hal ini diduga bahwa pada kondisi air tanah tersedia maupun pada kondisi cekaman kekeringan inokulasi FMA akan meningkatkan infeksi pada akar tanaman oleh mikoriza. Semakin tinggi tingkat infeksi mikoriza pada akar tanaman maka semakin banyak manfaat yang akan diperoleh tanaman dari infeksi mikoriza tersebut. Turk et al. (2006) mengatakan bahwa peran utama mikoriza adalah untuk menyediakan fosfor bagi akar tanaman yang terkena infeksi, karena fosfor adalah satu unsur yang tidak mobil di dalam tanah. FMA dapat menyerap $\mathrm{P}$ organik dan mengubahnya menjadi $\mathrm{P}$ anorganik yang dapat diserap tanaman dengan bantuan enzim fosfatase yang juga dihasilkan oleh FMA dan sel-sel tanaman tersebut.

Infeksi akar pada penelitian ini hanya ditemukan struktur FMA yang terdiri atas hifa internal dan eksternal, sedangkan vesikula dan arbuskula tidak ditemukan (Gambar 2). Struktur hifa, vesicular, dan arbuskular bisa terdapat dalam satu akar, tapi bisa juga salah satu atau dua struktur saja. Menurut Utobo et al. (2011) menyatakan tidak semua jenis mikoriza mampu membentuk struktur lengkap di dalam sel akar.

\section{SIMPULAN DAN SARAN}

\section{Simpulan}

Hasil uji pengaruh inokulasi FMA mampu meningkatkan pertumbuhan tanaman iler berdasarkan parameter tinggi tanaman, jumlah daun, jumlah cabang, luas daun, panjang akar, volume akar, bobot kering akar, jumlah spora, dan infeksi akar. Tingkat cekaman kekeringan yang optimal untuk pertumbuhan tanaman iler adalah cekaman kekeringan $90 \%$, hal tersebut berdasarkan pada parameter tinggi tanaman, jumlah daun, jumlah cabang, luas daun, panjang akar, jumlah spora, dan infeksi akar. Terdapat interaksi terbaik antara inokulasi FMA dan tingkat cekaman kekeringan 90\% terhadap pertumbuhan tanaman iler. Interaksi tersebut mampu meningkatkan tinggi tanaman, luas daun, jumlah spora, dan infeksi akar.

\section{Saran}

Penelitian dan pengkajian lebih mendalam sehingga dapat dijadikan anjuran sebagai Good Agricultural Practice (GAP) pada tanaman iler ataupun tanaman lainnya. Selin itu, Penelitian seperti ini perlu dikaji kembali pada tanaman iler dengan perlakuan tang berbeda tidak hanya pada kondisi cekaman kekeringan. 


\section{DAFTAR PUSTAKA}

Bucher M. 2007. Functional Biology of Plant Phosphate Uptake at Root and Mycorrhiza Interfaces. New Phytologist. 173(1): 11-26.

Hasnizar F. 2001. 'Pengaruh Endomikoriza dan Pupuk Fosfat terhadap Pertumbuhan Jambu Mete (Anacardium occidentale L.) pada Tanah Podsolik Merah Kuning'. Skripsi, (tidak dipublikasikan), Universitas Padjadjaran. Bandung.

Herawati T. 2009. Respons Pertumbuhan dan Produksi Kedelai (Glycine max L. Merrill) terhadap Fungi Mikoriza Arbuskula dan Perbandingan Pupuk Anorganik dan Organik. Skripsi, tidak dipublikasikan, Universitas Sumatera Utara. Medan.

Miska MEE. 2015. 'Respon Pertumbuhan Bibit Aren (Arenga Pinnata (Wurmb) Merr.) Terhadap Inokulasi Fungi Mikoriza Arbuskula Indigenous' [tesis]. Bogor (ID: Institut Pertanian Bogor.

Nurhalimah S, S Nurhatika, A Muhibuddin. 2014. Eksplorasi mikoriza vesicular arbuskular (MVA) Indigenous pada tanah regosol di Pamekasan, Madura. Jurnal Sains dan Seni Pomits. 3(1):3034.

Nusantara AD, Bertham YH, Mansur I. 2012. Bekerja dengan Fungi Mikoriza Arbuskula. Bogor (ID): IPB Press.

Puspitasari D, K Indah, H Anton. 2012. Eksplorasi Vesicular Arbuscular Mycorrhiza (VAM) Indigenus pada Lahan Jagung Sampang Madura. J. Sains dan Seni ITS Surabaya. 1(2): 19-22

Qalby AN, Djanggi J, Muhaedah. 2017. Isolasi dan identifikasi senyawa metabolit sekunder ekstrak kloroform daun tumbuhan iler (Coleus scutellarioides, Linn, Benth). Journal of Chemical Science. 18(1): 48-55.

Rahman MM, Saidy AR, Nisa C. 2019. Aplikasi mikoriza arbuskula untuk meningkatkan serapan fosfat, pertumbuhan dan produksi tanaman bawang merah (Allium ascalonicum L.). Enviro Scienteae. 15(1): 59-70.

Rewald B, L Holzer, H Goransson. 2015. Arbuscular Mycorrhiza Inoculum Reduces Root Respiration and Improves Biomass Accumulation of SaltStress Ulmus glabra Seedling. Urban Forestry dan Urban Greening. 14(2): 432437.

Sasli I. 2004. 'Peranan Mikoriza Vesikula Arbuskula (MVA) dalam peningkatan resistensi tanaman terhadap cekaman kekeringan'. Disertasi, (tidak dipublikasikan), Sekolah Pasca Sarjana. Institut Pertanian Bogor. Bogor.

Sastrahidayat IR. 2011. Rekayasa Pupuk Hayati Mikoriza dalam Meningkatkan Produksi Pertanian. Universitas Brawijaya Press. Malang.

Tjondronegoro PD, Gunawan AW. 2000. The Role of Glomus Fasciculatum and Soil Water Conditions on Growth of Soybean and Maize. J. Mikrobiol. Indonesia. 5 (1): 1-3.

Trisilawati O, Yusron M. 2008. Pengaruh pemupukan P terhadap produksi dan serapan $\mathrm{P}$ tanaman nilam (Pogostemon cablin Benth.). Balai Penelitian Tanaman Obat dan Aromatik. 19 (1): 39-46.

Turk MA, TA Assaf, KM Hameed, AM Al-Tawaha. 2006. Significance of micorrhizae. World J. of Agric. Sci. 2 (1): 16-20.

Utama MZH, Sudirman Y. 2003. Peranan mikoriza vesikula arbuskula, rhizobium dan asam humat pada pertumbuhan dan kadar hara beberapa spesies legum penutup tanah. Bul. Agronomi. 31 (3): 94-99.

Utobo EB, EN Ogbodo, AC Nwogboga. 2011. Techniques for Extraction and Quantification of Arbuscular Mycorrhizal Fungi. Libyan Agric. Res. Cen. J. Intl. 2(2): 68-78.

Widiastuti H, G Edi, S Nampiah, KD Latifah, HD Didiek, S Sally. 2003. Optimalisasi simbiosis cendawan mikoriza arbuskula Acaulospora tuberculata dan Gigospora margarita pada bibit kelapa sawit di tanah masam. Menara Perkebunan. 70(2): 50-57.

Wijaya WD, Yunus A, Parjanto, Widiyastuti Y. 2019. Pertumbuhan dan Hasil Beberapa Aksesi Tanaman Iler (Coleus atropurpureus (L) Benth) dengan Perlakuan Cekaman Kekeringan. Prosiding seminar nasional Fakultas Pertanian UNS.3(1) :52-59.

Xie X, B Weng, B Cai, Y Dong, C Yan. 2014. Effects of arbuscular mycorrhizal inoculation and phosphorus supplyon the growth and nutrient uptake of Kandelia obovata (Sheue, Liu dan Yong) seedlings in autoclaved soil. Applied Soil Ecology, 75, 162-171.

Yusriadi Y, Pata'dungan YS, Hasanah U. 2018. Kepadatan dan Keragaman Spora Fungi Mikoriza Arbuskula pada Daerah Perakaran Beberapa Tanaman Pangan di Lahan Pertanian Desa Sidera. Agroland: Jurnal Ilmu-ilmu Pertanian, 25(1):64-73. 